\title{
Peculiarities of Implementation of the Concept of Providing Quality of Drugs in Ukraine
}

\author{
K Smetanina* \\ Danylo Galitsky Lviv National Medical University, Ukraine \\ *Corresponding author: K Smetanina, Department of Danylo Galitsky Lviv National Medical University, Ukraine. \\ To Cite This Article: K Smetanina. Peculiarities of Implementation of the Concept of Providing Quality of Drugs in Ukraine. Am J Biomed Sci \& \\ Res. 2019 - 3(6). AJBSR.MS.ID.000725. DOI: 10.34297/AJBSR.2019.03.000725
}

Received: June 29, 2019 | Published: July 10, 2019

\section{Introduction}

The modern quality assurance of medicines covers the quality assurance of drugs, from the stage of their pharmaceutical development, research, through proper production, quality control, storage, implementation and the provision of information to the physician and patient. According to this concept, reliable guarantees of quality and safety of the drug should be provided at all stages of the drug life cycle.

The quality of each drug should be proven at the stages of preclinical studies and clinical trials, objectively evaluated in the case of state registration, securely secured in the course of industrial serial production, and constantly controlled in the wholesale, retail and medical applications. In the focus of the WHO's recommendations, all areas of the implementation of the concept of quality assurance of drugs should be aimed at meeting the needs of patients.

The aim of the work was to analyze the modern system of quality assurance of medicines at all stages of their advancement in the pharmaceutical market of our country and to focus on the main problems that hinder the transition of the domestic pharmaceutical industry to international and European standards.

Keywords: medicines, Goods Manufacturing Practice, quality system.

\section{Materials and Methods of Research}

In accordance with the goal, an analysis of the regulatory and legal framework and the current trends in the implementation of the principles and rules for the implementation of the quality assurance system of drugs in international practice and in the field of drug circulation in the pharmaceutical market of Ukraine was carried out. At the present stage, the generally accepted international system for the implementation of the quality assurance system of the drug is the introduction of the principles and rules of good practice of GxP, the observance of which is mandatory at all stages of the life cycle of the drug. According to international requirements, the drug must be developed in accordance with the requirements of Good Manufacturing Practice (GMP), preclinical studies should be performed in compliance with the rules of Good Laboratory Practice (GLP), clinical trials are performed on the basis of Good Clinical Practice (GCP) rules, the industrial production of drugs is implemented in accordance with with Good Manufacturing Practice (GMP) requirements, implement wholesale implementation in accordance with Good Distribution Practices (GDP) principles, retail sales of medicines are based on the rules of proper pharmacy practice (GPP) and all regulatory functions in the state are based on good regulatory practice (GRP). Each of the elements of GxP provides the main characteristics of the activity, outlines the general principles and approaches to the implementation of good practice, describes the methods and conditions for the implementation of these activities, requirements for the quality system, personnel, equipment, premises, documentation, validation, etc. All elements of the GxP system of good practices are closely interconnected and form a single chain whose strength is determined by its weakest link. In the event of a breach of the requirements of any good practice, the chain is interrupted, and the quality of the drugs is virtually impossible to guarantee and provide the requirements of good practice are used as the basic regulatory requirements that are mandatory for the pharmaceutical sector at the stages of development, research, production, storage, and implementation of the drug.

In the meantime, good practices should be applied not only to actors, but also to authorized bodies that carry out expert, supervisory and control functions in relation to the activity related to the circulation of drugs at all stages of the life cycle. In particular, the second edition of the WHO guidance document "Marketing authorization for medicines with an emphasis on multisource (generic) products"[1] published principles and rules of good regulatory practice, which should be followed by national regulators in the field of drug regulation, and which are obliged to Follow up to ensure the proper level of drug quality.

Based on the recommendations of the WHO in Ukraine, the Good Governing Practice Guide [2], issued by the Ministry of Health 
of Ukraine, was developed and approved, which reflects the mission, views, functions of authorized bodies and expert organizations of particular importance was the system of good practices in the field of quality assurance, which is based on a comprehensive system of preventive prevention in terms of prevention in the production, storage, implementation of even unconscious or random factors potentially able to change the effectiveness and safety of drugs, guaranteed by the appropriate level of development and study of the drug and presented in the materials of the registration dossier.

According to the requirements of GMP, the owner of the production license is required to produce the drug in a way that meets his purpose, the requirements of the registration dossier, and thus excludes the risk to patients arising from violations of safety, efficacy and quality requirements [3]. At the present stage, it is required from the subjects of the pharmaceutical sector that the principles of the GXP principles and rules are consistent with the organization of regulators' work in accordance with the appropriate regulatory practice (GRP) on the basis of international approaches, in particular with the documents of the International Conference on Harmonization of Technical Requirements for the Registration of Medicinal Products for Human Use ( CCI) - Q8 (Pharmaceutical Development), Q9 (Quality Risk Management) and Q10 (Pharmaceutical Quality Systems). One of the key elements of the quality assurance system is the implementation of production in accordance with the requirements of Good Manufacturing Practice (GMP). According to the WHO definition, GMP is part of the concept of quality assurance, which ensures the production and control of products according to quality standards, in accordance with their application and purpose, as well as the requirements of the registration dossier. Ukrainian normative acts define the GMP as part of the quality assurance system, which ensures that drugs are constantly produced and controlled by the quality standards that are appropriate for their purpose, as well as in accordance with the requirements of the registration dossier and the specification for these products [3].

Inadequate medical devices not only represent a danger to the health of people, but also pose material damage to both the state and consumers. In this regard, the introduction of GMP requirements as a fundamental element in the quality assurance system is important economic value. GMP rules have been adopted in the European Union (EU) Directive 91/356/EEC (with subsequent amendments and modifications) The current requirements for the production of EU GMP drugs are approved by Directive 2003/94, and the detailed rules are published in the EU guidelines (Vol. 4 EudraLex). GMP requirements are mandatory for obtaining a license and for the production of medicines in the EU countries, as well as for the manufacture of drugs that import into the EU and export from the EU. In the case of the export of medicines to the EU, GMP certificates issue licensing authorities at the request of the exporter without additional inspection [4]. To date, virtually all countries of the world have legislated at a legislative level that oblige GMP to comply with the requirements for the production of medicines for both domestic producers and importers.

An important role played by international and European GMP requirements in the process of formation of the pharmaceutical industry of Ukraine. The progress of Ukraine towards the EU integration depends to a certain extent on the introduction of a system of technical regulation of access to the market in accordance with international and European standards. In Ukraine there is a gradual harmonization of national legislation with international and European rules and requirements, including to pharmaceutical production. Within the framework of this process, Ukraine's legislation on the quality assurance of medicines is being adapted in accordance with the normative acts adopted by the EU. To date, a number of official guidelines have been adopted in Ukraine that include requirements for the quality assurance of medical devices that have the status of industry standards The requirements of GMP in 2011 were the basis for licensing conditions for conducting economic activities for the production of drugs [5].

In Ukraine, there are a number of powerful licensed companies that are actively introducing innovative technologies, new products, quality assurance system, GMR principles and rules. Leading pharmaceutical companies have successfully passed the certification of production to meet the requirements of GMP both at the national level and inspectorates of other countries. In 2013, Ukraine joined the WHO International Drug Trade Certification System. The GMP requirements are fundamental in WHO's proposed international quality certification system for international trade. In accordance with the requirements of the System of Certification of Medicinal Products for International Trade, WHO in Ukraine carries out certification of drugs that export Ukrainian pharmaceutical companies to other countries. Important role in quality assurance is played by the introduction of integrated systems by ISO / GMP quality management. To date, quality management is a business card of every enterprise whose products are marketed. There are now more than 1 million enterprises in different industries that have been certified to comply with the requirements of IS09001 Quality Management Systems. The interest of companies to certify in accordance with ISO 9000 requirements is conditioned by the desire to enter the foreign markets, as well as the requirements of consumers to create a certified quality management system.

To meet current requirements, companies around the world are forced to implement multiple management systems at the same time. Otherwise - difficult search for trading partners, low chances of participation in tenders, etc. This problem can be successfully solved by introducing integrated management systems (ISMs) at pharmaceutical companies. International management systems are the basis of an integrated management system. International management systems that can build an effective integrated management system include: IS09001: 2011 (DSTU ISO9001: 2011) - Quality Management Systems; DSTU IS09004: 2012 - Quality management systems. Management to achieve the long-term success of the organization. An approach based on quality management (IS09004: 2009, IDT); ISO14001: 2004 (DSTU IS014001: 2006) - Environmental Management Systems. Requirements and guidelines for application; OHSAS18001: 2007 (DSTU OHSAS18001: 2010) - Hygiene management systems1 and labour safety. Requirements (OHSAS18001: 2007, IDT); ISO22000: 2005 (DSTU ISO22000: 2007)-Food Safety Management Systems. Requirements for any food chain organization; ISO13485: 2003 
(LSTU IS013485: 2005) - Medical products. Quality management systems. Regulatory requirements; DSTU ISO/IEC 17025: 2006 General requirements for the competence of testing and calibration laboratories etc. With confidence it can be argued that the quality management system in accordance with the requirements of IS09001 in conditions of market instability is an effective management model that enables to respond promptly to changes in the market environment and also is an effective tool) for analysing the work of an enterprise that enables identification of risks and take measures to ensure the concept of quality.

\section{References}

1. WHO (2011) Marketing authorization of pharmaceutical products with special reference to multisource (generic) products: a manual for National Medicines Regulatory Authorities (NMRAs). Geneva, USA.
2. On Approval of Documents on Quality Assurance of Drugs (2009) Instruction ST-N MOHU 42-4.0: 2008 "Medicines - Good Manufacturing Practice.

3. (2010) Smetanina KI Fundamentals of Standardization and Certification of Medicines. New Book, Ukraine pp.360.

4. Order of the Ministry of Health of Ukraine (2011) № 723 “On approval of Licensing conditions for the conduct of economic activities for the production of medicinal products, wholesale, retail trade in medicinal products" / Official site of the Cabinet of Ministers of Ukraine, Ukraine.

5. M. Lyapunov, A Bezugla, O. Solovyov and others (2011) ST-N MOHU 424.3: 2011- Medicines. Pharmaceutical quality system (CCI Q10)/- K. Ministry of Health of Ukraine pp.30. 